\title{
A Compact Fractal-Shaped O-Ring Monopole Antenna for Modern Broadband Wireless Applications
}

\author{
${ }^{1}$ CHANG-JU WU, ${ }^{2}$ I-FONG CHEN, ${ }^{3}$ CHIA-MEI PENG, ${ }^{2}$ WEN-YI TSAI, ${ }^{1}$ JWO-SHIUN SUN \\ ${ }^{1}$ Dept. of Electronic Engineering National Taipei University of Technology 1, Sec. 3, Zhongxiao E. \\ Road, Taipei 10608 TAIWAN, R.O.C. \\ ${ }^{2}$ Dept. of Computer and Communication, Jinwen University of Science and Technology. No. 99, An- \\ Chung Road, Hsin-Tien District, 23154 New Taipei City, TAIWAN, R.O.C. \\ ${ }^{3}$ Dept. of Communication Engineering, Feng Chia University. No. 100 Wenhwa Rd. Seatwen Dist. \\ 40724 Taichung, TAIWAN, R.O.C.
}

\begin{abstract}
In this letter, the design of a compact planar Fractal-shaped O-ring monopole antenna based on the Sierpinski carpet concept is studied and proposed for modern broadband wireless applications. The planar fractal-shaped O-ring monopole antenna is on the basis of Sierpinski category construction and then modifies the state of the plane inward with a radius of $27 \mathrm{~mm}$ over the two iterations. The antenna structure is low profile and easy to be fabricated, and it has performed the simulation and measurement with the result VSWR $\leq 2$ that can achieve a wide impedance bandwidth $636 \%$ from the frequency band $1.57 \mathrm{GHz} \sim 10 \mathrm{GHz}$. The geometric scale factor of the Sierpinski fractal is according to the same scale element that defines the geometrical selfsimilarity. In our experiments, the results show that use of fractal-shaped O-ring into monopole antenna structure can effectively improve input impedance matching, and obtain a larger bandwidth and better radiation pattern, while also having predictable multi-band characteristics.
\end{abstract}

Key-Words: - Fractal, Sierpinski, Broadband monopole.

Received: February 9, 2021. Revised: July 13, 2021. Accepted: July 31, 2021. Published: August 24, 2021.

\section{Introduction}

Wireless products have to be attractive, lightweighted and at the right size. It is a trend in the development of wireless devices. In recent years, wireless technology has developed rapidly, and it is foreseeable that the wireless system needs to support a greater coverage bandwidth, such as Global Positioning System (GPS, 1575MHz), Mobile Wireless Communication system(2G/3G/4G) bands operating at $698-960$ $\mathrm{MHz} / 1710-2690 \mathrm{MHz}$, wireless local area network (WLAN) bands operating at 2.4-2.484 GHz/5.15$5.825 \mathrm{GHz}, 6 \mathrm{GHz}$ unlicensed spectrum for the European markets between $5.925 \mathrm{GHz}$ to $6.425 \mathrm{GHz}$, for the US markets between $5.925 \mathrm{GHz}$ to $7.125 \mathrm{GHz}$, and Sub- $6 \mathrm{GHz} 5 \mathrm{G}$ bands operating at $3.5 \mathrm{GHz} / 4.7 \mathrm{GHz}$. According to the market demand and trend, a wider or multiple band antenna design for modern broadband wireless applications has become more and more popular. Challenges of how to miniaturize them, especially for highly integrated modern broadband wireless applications arise.

There are many antenna structures in the papers [13] that can meet broadband requirements, such as bow tie dipole, bow tie slot and spiral structures. However, the size of these antennas will be a challenge to be integrated in modern wireless applications. In order to minimize the impact of this dimension challenge, the circular disc monopole structure was proposed [4], but its size still needs to be miniaturized. In our studies, many broadband antenna articles [5-6] have chosen ultrawideband(UWB) wireless technology to demonstrate their antenna design and performance achievements because UWB has been permitted by U.S. Federal Communication Commission (FCC). Its frequency range has been allocated from $3.1 \mathrm{GHz}$ to $10.6 \mathrm{GHz}$; nevertheless, it can't effectively satisfy the current wireless system applications, especially for lower frequency band from $1-3 \mathrm{GHz}$.

The Sierpinski gasket is a fractal named after the Polish mathematician Waclaw Sierpinski who described it in 1916 [7]. The original Sierpinski gasket is constructed by subtracting a central inverted triangle from a main triangle shape. After the subtraction, three equal triangles remain on the structure, each one being half of the size of the original one [8]. Printed fractal antennas have attracted much attention in wireless communication because of their low profile and the easiness to be fabricated [9-11]. These papers have shown that the proposed antennas can be miniaturized and obtain wider input impedance matching. 


\section{Contribution}

In this paper, a compact planar fractal monopole antenna for modern broadband wireless application is demonstrated. The novelty in the structure is brought by introducing an O-ring fractal-shaped with 2 iterations of self-similarity inside, which facilitates in extending the impedance bandwidth. A significant contribution of the presented paper is:

- The proposed antenna achieves a 6.36:1 wide impedance bandwidth with 2:1 VSWR from $1.57 \mathrm{GHz} \sim 10 \mathrm{GHz}$ and the simulation and experimental results are studied and analyzed.

Details of the proposed antenna and its performances are given in the next two sections.

\section{Antenna Design and Parametric Studies}

\subsection{Antenna Configuration}

Fig. 1 depicts the basic geometry of the proposed planar fractal-shaped O-ring monopole antenna, which was modified by Sierpinski category fractal, and plotted the inward iteration. The antenna overall height of $h_{n}$ is $54 \mathrm{~mm}$, and the Sierpinski fractal has the scale factor as given

$$
\delta=\frac{h_{n+1}}{h_{n}}=0.33
$$

where $n$ represents the iteration and $h$ represents the height of the O-ring.

The proposed antenna has different scale factors by the 1 st and 2 nd iteration. It is fabricated on a thickness of $0.8 \mathrm{~mm}$ FR4 glass epoxy substrate (the relative permittivity is 4.4) with its outer radius $27 \mathrm{~mm}$ and inner radius $26 \mathrm{~mm}$. The iterative variation of the O-ring $\varnothing a, \varnothing b, \varnothing c$ is equal to $54 \mathrm{~mm}, 18 \mathrm{~mm}, 6 \mathrm{~mm}$, respectively. A circular aluminum plate with radius $R g=35 \mathrm{~mm}$ and thickness $W g=0.8 \mathrm{~mm}$ was used for grounding plane. The proposed antenna radiator between ground plate the gap $=0.8 \mathrm{~mm}$, and the RF SMA connector was connected through the ground plate center point of circle and antenna radiation element directly. The geometric structure and dimensions of the proposed antenna was simulated by using electromagnetic simulator Ansoft HFSS. The final optimized parameters of the antenna are listed in Table I.

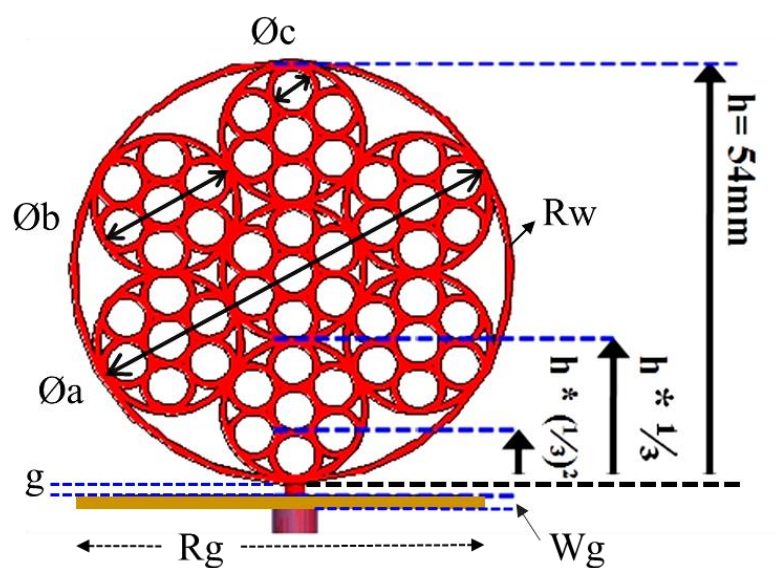

Fig.1: Geometry and dimension of a compact planar fractal-shaped O-ring monopole antenna.

Table 1. Optimized dimensions of the proposed antenna.

\begin{tabular}{|l|c|c|c|c|}
\hline Parameters & $R w$ & $W g$ & $g$ & $R g$ \\
\hline Value $(\mathrm{mm})$ & $\mathbf{1}$ & $\mathbf{0 . 8}$ & $\mathbf{0 . 8}$ & $\mathbf{7 0}$ \\
\hline Parameters & $\varnothing a$ & $\varnothing b$ & $\varnothing c$ & \\
\hline Value $(\mathrm{mm})$ & $\mathbf{5 4}$ & $\mathbf{1 8}$ & $\mathbf{6}$ & \\
\hline
\end{tabular}

\subsection{Antenna Design Guideline}

The first strategy is to decide the circle radius and total height of the O-ring monopole antenna. From here we know the lower band edge frequency of printed monopole antenna can be estimated by the standard formulation [12-13]. If $L$ is the height and $r$ is the effective radius of the planar monopole antenna in centimeters, which is determined by equating area of the planar and cylindrical monopole antennas, then the lower band edge frequency $f_{L}$ is given as

$$
f_{L}=\frac{c}{\lambda}=\frac{7.2}{(L+(t \times r)+p)} \quad G H z
$$

where $c$ is the velocity of light in free-space, $\lambda$ is the free-space wavelength. $p$ is the length of the $50 \Omega$ feed line and $t$ is the PCB thickness in centimeters.

According to the formulation (2), the printed monopole antenna of the O-ring height and the size of the ground plate can be approximately calculated to be $50 \mathrm{~mm}$. After calculation, $f_{L}=1.364 \mathrm{GHz}$ is obtained and it meets the research requirement for the lowest frequency of desired band in the initial O-ring monopole antenna. In order to effectively implement the iteration variation of fractal with simulation and measurement, we adjusted the outer circle diameter to $54 \mathrm{~mm}$ and the inner circle diameter to $53 \mathrm{~mm}$, making the circumference trace 
width to be $1 \mathrm{~mm}$. The planar fractal monopole antenna was modified by the Sierpinski carpet concept, which is generated through using two iterations of the decomposition algorithm on the Oring antenna, named initiator. Compared to the structure of three antennas, the initiator and iterators are generated by the geometric ratio of the O-ring that requires the midpoint of the circles to be merged in the same place. The first iteration shrinks the circle to $1 / 3$ diameter to generate it, and the second iteration uses the Sierpinski carpet algorithm to obtain a circle with twice mathematics (equal to $1 / 9$ diameter). The proposed antenna structure evolution is shown in Fig. 2.

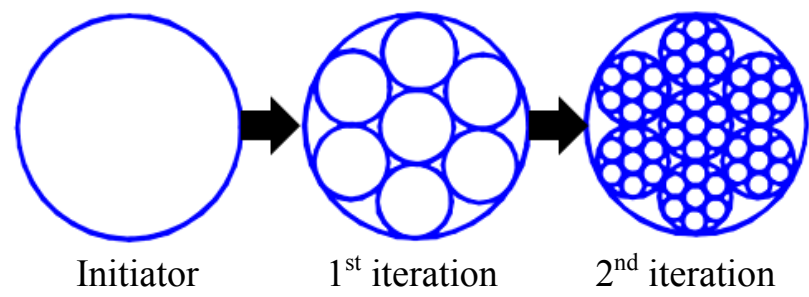

Fig.2: The Iteration of compact planar fractalshaped O-ring based on the Sierpinski carpet concept.

\subsection{Parametric Studies}

The key parameters $\varnothing a(\mathrm{~N}=0), \varnothing b(\mathrm{~N}=1), \varnothing c(\mathrm{~N}=2)$, and $g$ that affect the resonance frequencies and bandwidth are studied in this section.

Fig 3. shows the relationship between the parameters $\varnothing a, \varnothing b, \varnothing c$ and the bandwidth. Note that the bandwidth can be significantly improved when the O-ring parameters $\varnothing a, \varnothing b$ and $\varnothing c$ are properly adjusted. As a result, the $f_{L}$ of initiator is trendily closed to $1.3 \mathrm{GHz}$ that almost matches the formulation calculation for $\left|S_{11}\right| \leq-10 \mathrm{~dB}$. Moreover, the 1st iteration can improve the bandwidth from $1.57 \mathrm{GHz} \sim 4.93 \mathrm{GHz}$ and the 2nd iteration is greater in amount for the bandwidth from $1.65 \mathrm{GHz} \sim 9.85 \mathrm{GHz}$. Meanwhile, it's also observed when the number of iterations gradually increases that $f_{L}$ will be $5 \sim 10 \%$ higher than the lowest frequency before iterating.

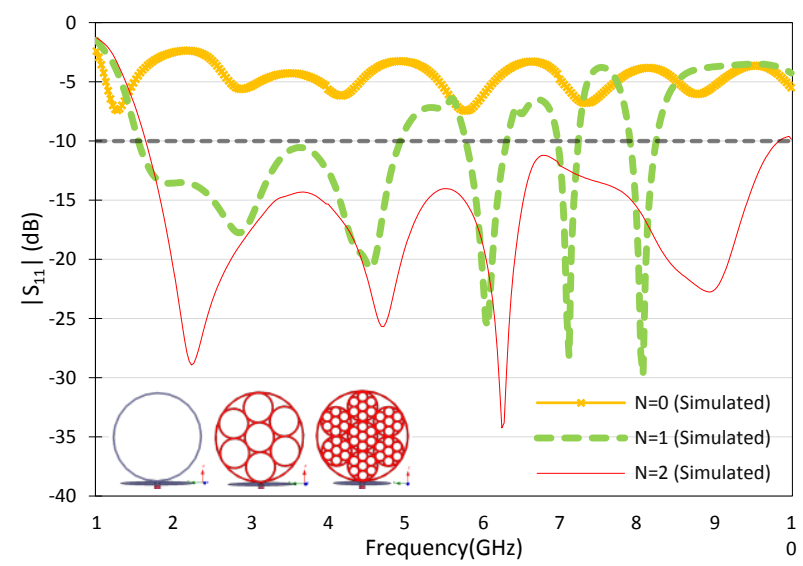

Fig.3: Simulated reflection coefficient of the proposed antenna in different iterations.

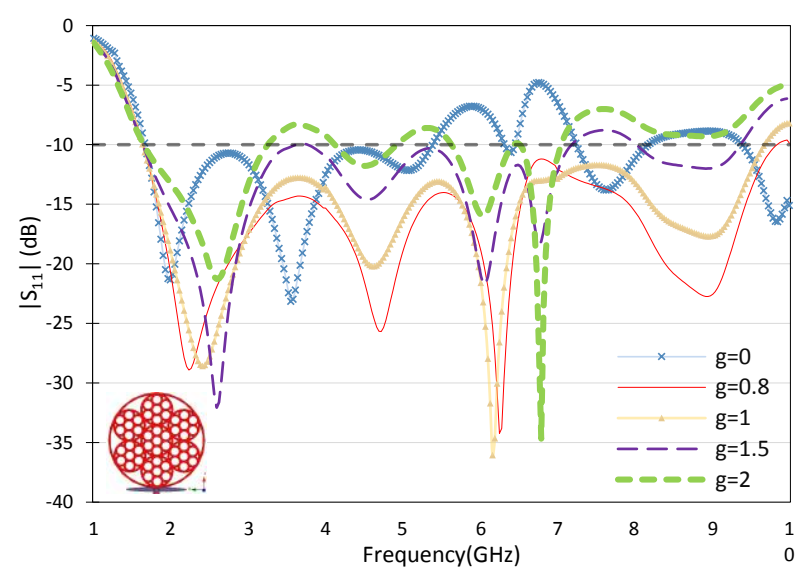

Fig.4: Simulated reflection coefficients at different value of $g$.

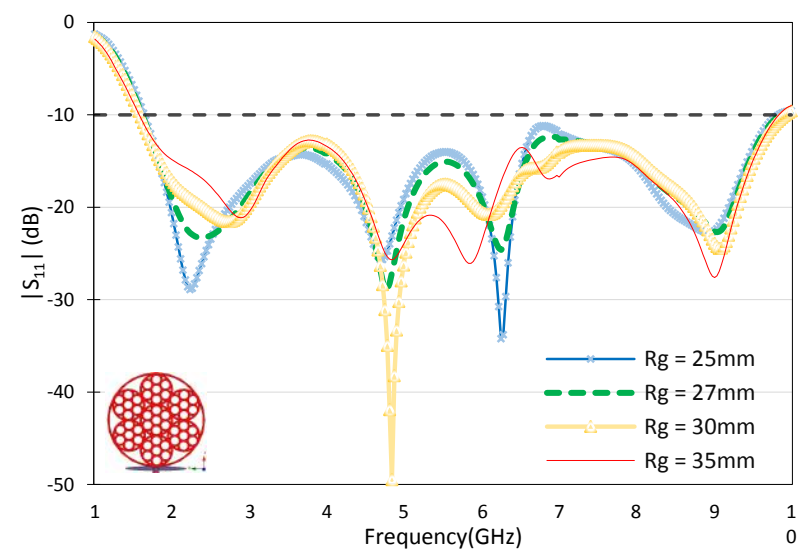

Fig.5: Simulated reflection coefficients at different value of $R g$. 
Fig. 4 shows the relationship between the parameter $g$ and bandwidth. It can be seen that the best impedance bandwidth from $1.65 \mathrm{GHz}$ to $9.85 \mathrm{GHz}$ is $g=0.8 \mathrm{~mm}$, and a larger or smaller gap distance will gradually decrease the bandwidth performance. To realize the bandwidth coverage for the lowest frequency $1.57 \mathrm{GHz}$ as the initial research purpose, the radius of the ground plate the parameter $R g$ needs to be adjusted appropriately. For different $R g$, the reflection coefficient curve of the antenna is almost unchanged. However, it can be seen that $f_{L}$ is slighted moved to the lower band with limited changes. The relationship between the parameter $R g$ and the bandwidth is shown in Fig. 5.

\subsection{Current Distributions}

The simulated current distributions of the initiator and the 1st and 2nd iteration fractal-shaped O-ring monopole antennas are demonstrated in Fig. 6. It can be seen that the wide impedance bandwidth of the 1 st and 2nd iteration antennas are getting better and better. The reason is that the number of iterations increases, the contact area of the fractal surface current path becomes larger. Fig. 7(a) shows the current density near the second resonance at $4.7 \mathrm{GHz}$, indicates approximately a second order harmonic. Fig. 7(b) illustrates a more complicated current density at $6.25 \mathrm{GHz}$, corresponding to the third order harmonic.

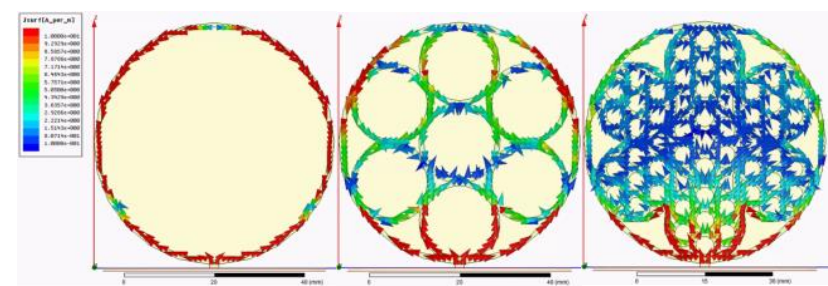

Fig.6: The proposed antenna Current Distribution at different iterations at $2.41 \mathrm{GHz}$. (a)

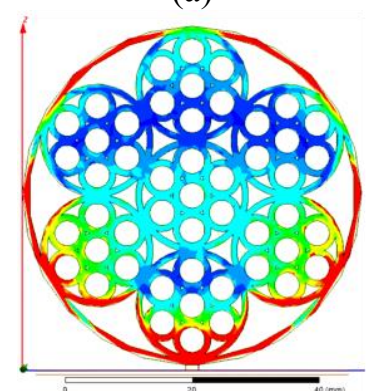

(b)

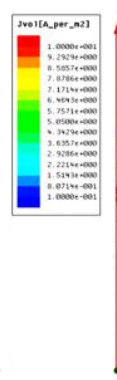

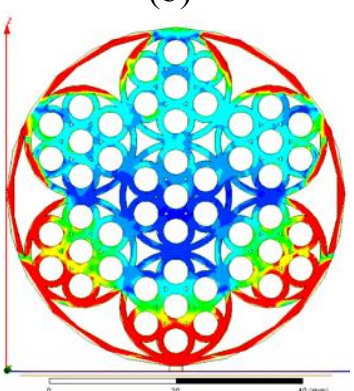

Fig.7: The Current Density of the proposed antenna for (a) $4.7 \mathrm{GHz}$ and (b) $6.25 \mathrm{GHz}$.

\section{Simulated and Measured Results}

The proposed antenna prototype fabricated with eagle view is shown in Fig. 8. Meanwhile, the simulation and measurements were carried out to demonstrate the performances. The simulated and measured VSWR are shown in Fig. 9. The impedance bandwidth results with VSWR $\leq 2$ are $597 \%$ and $636 \%$ for the lowest frequency at $1.65 \mathrm{GHz}$ and $1.57 \mathrm{GHz}$, respectively.
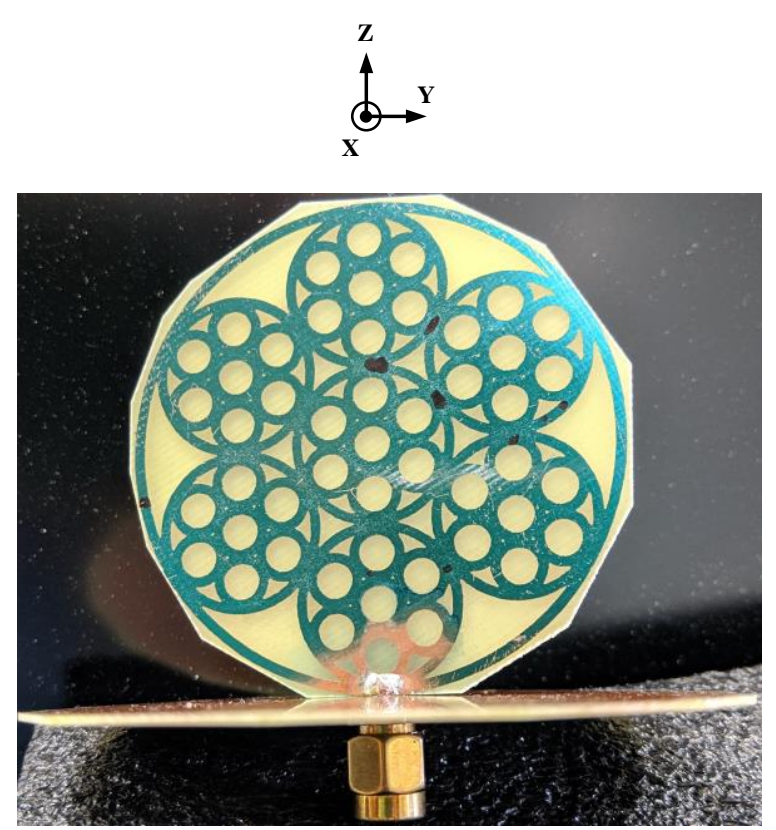

Fig.8: Fabricated prototype of the proposed antenna.

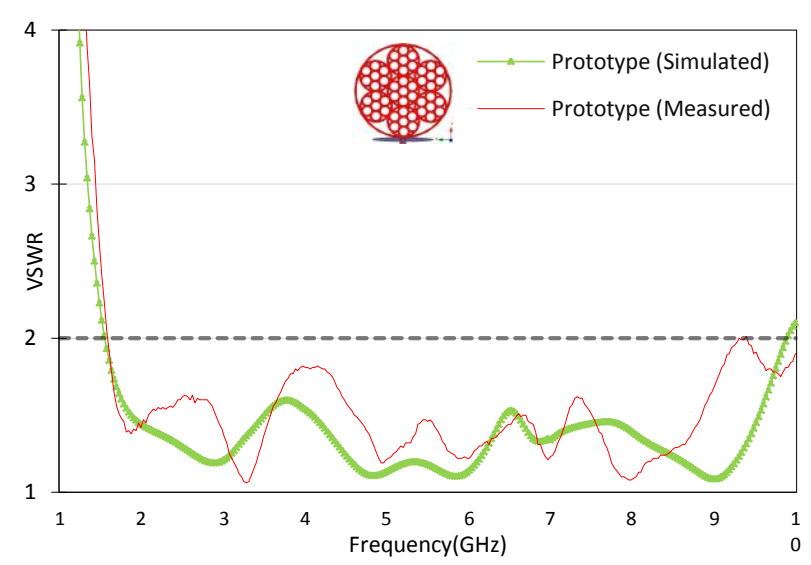

Fig.9: Measured and simulated VSWR of the proposed antenna. 
The radiation patterns have been simulated and also measured inside a 3D anechoic chamber. The measured and the simulated normalized radiation patterns at 1.57, 2.4 3.7, 4.5, 5.8, 6.5 and $7.12 \mathrm{GHz}$ are plotted in Figs. $10-16$ respectively. The measured xy-plane patterns are very close to those obtained in the simulation. It is noticed that the xyplane pattern is omnidirectional at lower frequencies $(1.57,2.4 \mathrm{GHz})$ and begins to deform into an elliptic-shape radiation pattern at mid-higher frequencies $(3.5,4.7,5.8 \mathrm{GHz})$ and at the highest frequencies $(6.5,7.12 \mathrm{GHz})$, a defective circularshape radiation pattern is formed. The measured xzplane patterns follow the shapes of the simulated ones, though the agreement is not as good as the xyplane patterns. In the xz-plane, the simulated and measured radiation pattern has a little error at $3.5 \mathrm{GHz}$ and higher frequencies. That should be precision differences in the antenna fabrication like the gap between antenna and ground plate or feed connector. The simulated xz-plane pattern is like a traditional monopole at 1.57 and $2.4 \mathrm{GHz}$. With the increase of frequency $(3.5 \mathrm{GHz}$ and higher frequencies), it starts to form notches and get more directional at around $\pm 45^{\circ}$ from the Z-direction.

Fig. 17 illustrates the measured peak gain and efficiency of the proposed antenna. It is shown that the maximum gain occurs at the direction of $\theta=90^{\circ}$ when the frequency is equal and lower than $3 \mathrm{GHz}$; at higher frequencies (from 3.5 to $7.12 \mathrm{GHz}$ ), the peak gain will be shifted from xz-plane to yx-plane and it shifts to the direction when $\theta= \pm 30^{\circ}$ and ranges from 3.34 to $6.55 \mathrm{dBi}$ due to the more directional radiation properties.

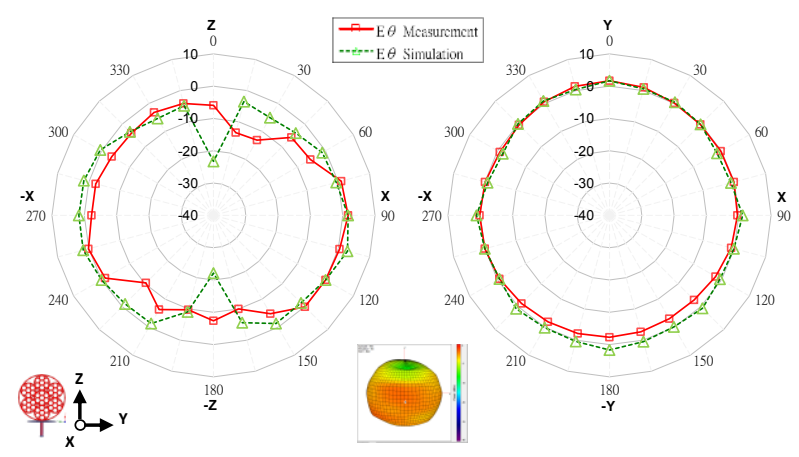

Fig.10: Measured and simulated normalized radiation patterns of the antenna at $1.57 \mathrm{GHz}$ in $\mathrm{xz}-$ plane(Left) and xy-plane(Right).

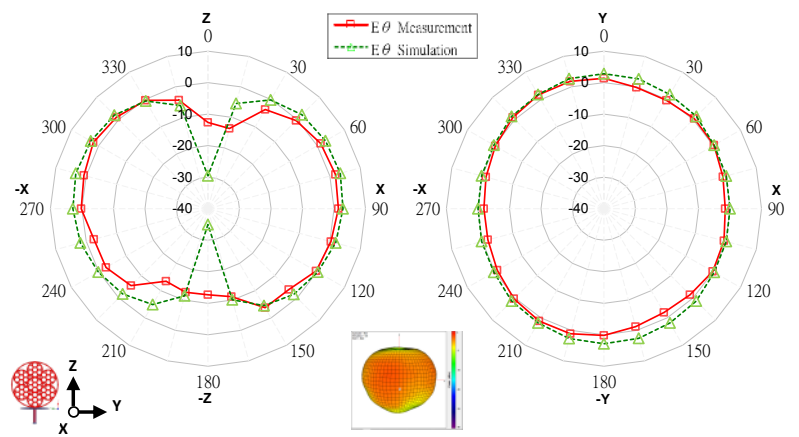

Fig.11: Measured and simulated normalized radiation patterns of the antenna at $2.4 \mathrm{GHz}$ in $\mathrm{xz}-$ plane(Left) and xy-plane(Right).

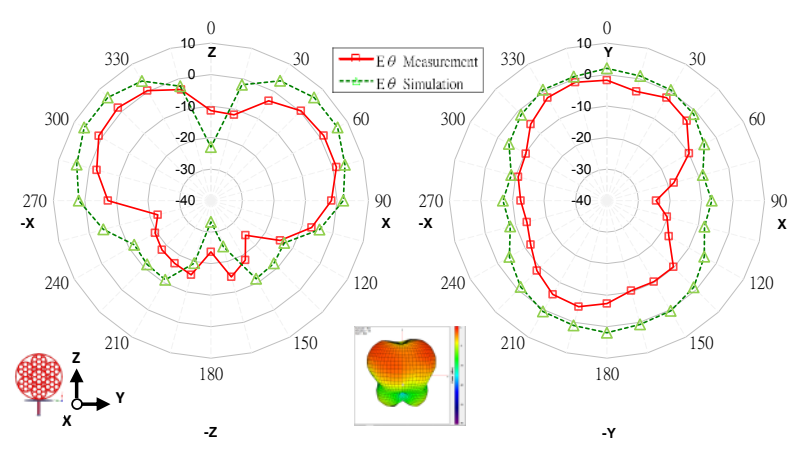

Fig.12: Measured and simulated normalized radiation patterns of the antenna at $3.5 \mathrm{GHz}$ in $\mathrm{xz}-$ plane(Left) and xy-plane(Right).

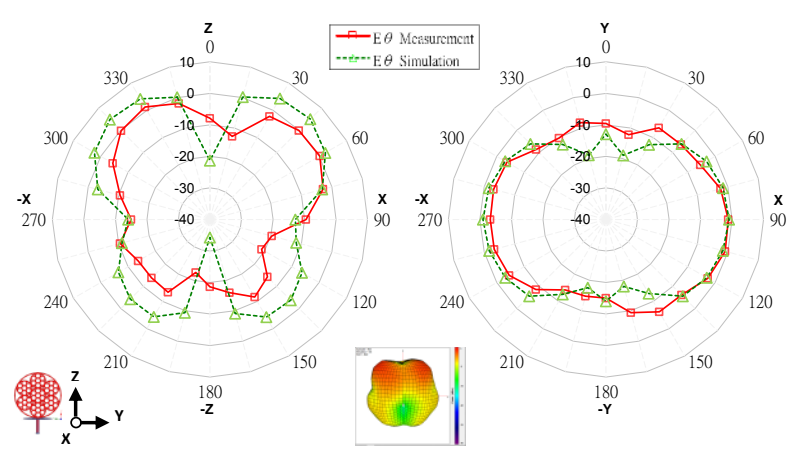

Fig.13: Measured and simulated normalized radiation patterns of the antenna at $4.7 \mathrm{GHz}$ in $\mathrm{xz}-$ plane(Left) and xy-plane(Right). 


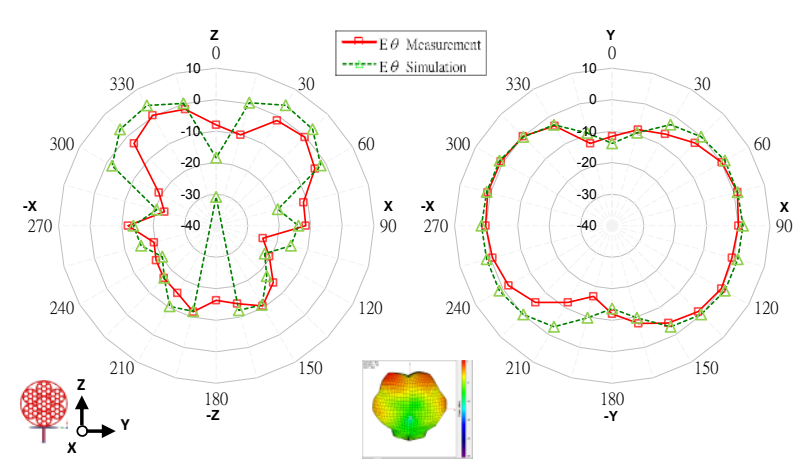

Fig.14: Measured and simulated normalized radiation patterns of the antenna at $5.8 \mathrm{GHz}$ in $\mathrm{xz}$ plane(Left) and xy-plane(Right).

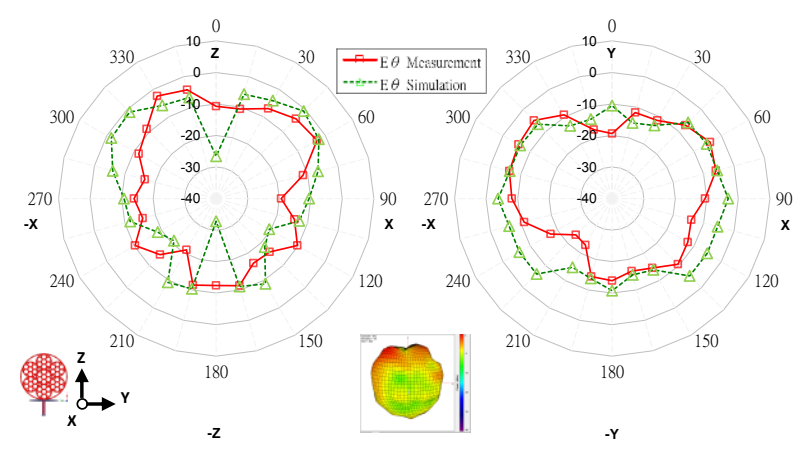

Fig.15: Measured and simulated normalized radiation patterns of the antenna at $6.5 \mathrm{GHz}$ in $\mathrm{xz}-$ plane(Left) and xy-plane(Right).

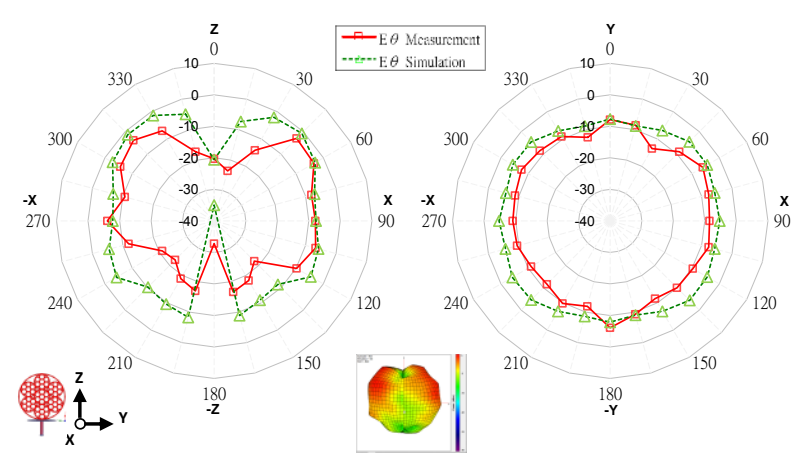

Fig.16: Measured and simulated normalized radiation patterns of the antenna at $7.12 \mathrm{GHz}$ in $\mathrm{xz}-$ plane(Left) and xy-plane(Right).

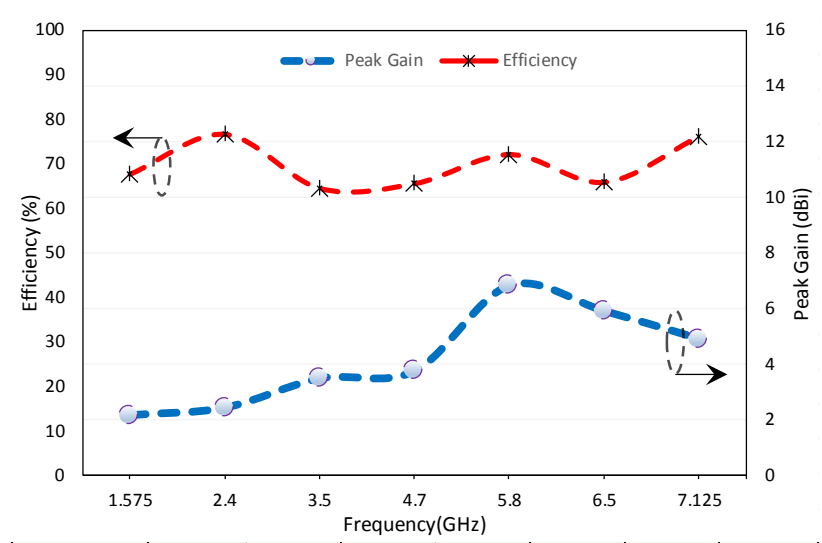

\begin{tabular}{|l|l|l|l|l|l|l|l|} 
Frequency & $1.575 \mathrm{GHz}$ & $2.4 \mathrm{GHz}$ & $3.5 \mathrm{GHz}$ & $4.7 \mathrm{GHz}$ & $5.8 \mathrm{GHz}$ & $6.5 \mathrm{GHz}$ & $7.125 \mathrm{GHz}$ \\
\hline
\end{tabular}

\begin{tabular}{|c|c|c|c|c|c|c|c|}
\hline Peak Gain(dBi) & 2.1 & 2.4 & 3.5 & 3.7 & 6.8 & 5.9 & 4.9 \\
\hline
\end{tabular}

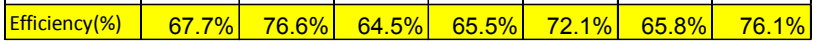

Fig. 17: Measured \& Simulated antenna peak gain \& efficiency versus frequency of the proposed antenna.

\section{Conclusion}

A compact planar Fractal-shaped O-ring monopole antenna based on the Sierpinski carpet concept for modern broadband wireless applications is presented in this paper. The antenna structure is low profile and ease of fabrication, and it has achieved a $636 \%$ wide impedance bandwidth from the frequency band $1.57 \mathrm{GHz} \sim 10 \mathrm{GHz}$ for $\mathrm{VSWR} \leq 2$. The geometric scale factor of the Sierpinski fractal is according to the same scale element that defines the geometrical self-similarity. In our experiments, the simulated and measured results are in good agreement and the results show that use of fractalshaped O-ring into monopole antenna structure can effectively improve input impedance matching, obtain a larger bandwidth and better radiation pattern. This antenna is applicable in many systems such as mobile home gateways, Picocell, etc.

\section{Future Work}

To be enhanced the practicability and flexibility of the proposed antenna in mainstream wireless technology. The focus of future work is summarized.

- Miniaturization, and single side with ground plane structure.

- Dual-polarization or MIMO capability.

- Directivity and stable the radiation gain in the whole impedance bandwidth. 


\section{References:}

[1] C.-M. Peng, I.-F. Chen, C.-C. Hung, and H.-C. Chen, "Printed modified bow-tie dipole antenna for multi-band applications," IEICE Transactions on Communications, vol. 92, no.4, pp.1404-1405, 2009.

[2] Chang-Ju Wu,I-Fong Chen, Chia-Mei Peng, Jwo-Shiun Sun, "A Dual Polarization Bow-Tie Slot Antenna For Broadband Communications," The International Journal of Engineering and Science (IJES), Volume 7, Issue 6 Ver. I, Pages 49-56, 2018-06.

[3] J.D. Dyson, "The Equiangular Spiral Antenna," IRE Transactions on Antennas and Propagation, 1959: 181-187.

[4] Qiu Jinghui;Qi Jiaran, "Study on the properties of circular monopole antenna," 2006 6th International Conference on ITS Telecommunications, IEEE conferences, year: 2006.

[5] Jianxin Liang;C.C. Chiau;Xiaodong Chen;C.G. Parini, "Study of a printed circular disc monopole antenna for UWB systems," IEEE Trans. Antennas Propag., vol. 53, issue 11, pp. 3500-3504, Nov. 2005.

[6] Rezaul Azim;Mohammad Tariqul Islam;Norbahiah Misran, "Printed circular ring antenna for UWB application," International Conference on Electrical \& Computer Engineering (ICECE 2010), IEEE conferences, year: 2010.

[7] Sierpiński, W.: Sur une courbe cantorienne qui contient une image biunivoque et continue de toute courbe donnée. C. r. hebd. Śeanc. Acad. Sci., Paris 162, 629--632 (1916).

[8] C. Puente-Baliarda;J. Romeu;R. Pous;A. Cardama, "On the behavior of the Sierpinski multiband fractal antenna," IEEE Trans. Antennas Propag., vol. 46, issue 6, 1998.

[9] N. Naresh Kumar;K. Saran Krishna;Yogesh K. Choukiker;S.K. Behera, "Compact modified Sierpinski fractal monopole antenna for multiband wireless applications," 2014 International Conference on Communication and Signal Processing, IEEE conferences, year: 2014.

[10] Aliakbar Dastranj, Fatemeh Ranjbar, and Mosayeb Bornapour, "A New Compact Circular Shape Fractal Antenna for Broadband Wireless applications," Progress In Electromagnetics Research C, Vol. 93, 19-28, 2019.

[11] Naresh K. Darimireddy, R. Ramana Reddy, A. Mallikarjuna Prasad, "A Miniaturized Hexagonal-Triangular Fractal Antenna for
Wide-Band Applications," IEEE Antennas and Propagation Magazine, vol. 60, issue 2, 2018.

[12] N.P. Agrawall;G. Kumar;K.P. Ray, "Wideband planar monopole antennas," IEEE Trans. Antennas Propag., vol. 46, issue 2, 1998.

[13] K. P. Ray; S. S. Thakur; R. A. Deshmukh, "Broadbanding a printed rectangular monopole antenna," 2009 Applied Electromagnetics Conference (AEMC), IEEE conferences, year: 2009.

\section{Creative Commons Attribution License 4.0 (Attribution 4.0 International, CC BY 4.0)}

This article is published under the terms of the Creative Commons Attribution License 4.0 https://creativecommons.org/licenses/by/4.0/deed.en_US 